\title{
Stigma against patients with HIV/AIDS in the rapid expansion of antiretroviral treatment in large drug injection-driven HIV epidemics of Vietnam
}

Phung Quoc Tat Than ${ }^{1 *}$, Bach Xuan Tran ${ }^{2,3}$, Cuong Tat Nguyen ${ }^{1}$, Nu Thi Truong ${ }^{4}$, Thao Phuong Thi Thai ${ }^{5}$, Carl A. Latkin ${ }^{3}$, Cyrus S. H. Ho ${ }^{6}$ and Roger C. M. Ho $0^{4,7}$

\begin{abstract}
Background: Despite existing efforts to provide antiretroviral treatment (ART) for all HIV-diagnosed people, stigma deprives them of the highest attainable health status and challenges the effectiveness of ART program in Vietnam. This study aimed to assess five dimensions of HIV-related stigma and explore its associated factors among ART patients in a multisite survey. Implications of this study support the development of HIV policies to improve patients' access, utilization, and outcomes of ART program toward the 90-90-90 goal in Vietnam.

Methods: A total of 1133 ART patients who were recruited by convenience sampling method from 8 ART clinics in Hanoi and Nam Dinh in a cross-sectional study from January to August 2013. Multivariate logistic regression was employed to identify factors associated with stigmatization.

Results: The majority of participants reported experiencing stigmatization due to shame (36.9\%), blame/judge (21.6\%), and discrimination (23.4\%). Further, $91.5 \%$ of participants disclosed their HIV status with others. The likelihood of experiencing stigmatization did not only associate with the patients' socioeconomic status (e.g., age, occupation, education) and HIV status disclosure, but also their health problems. Those with anxiety or depression and perceived lower quality of life were more likely to experience stigma.

Conclusions: To maximize the efficiency of the ART program, it is essential to develop interventions that reduce stigma involving individuals, families, and communities, and recognize and address complex health problems especially those patients showing depressive symptoms. Increasing quality of life of HIV-positive patients by providing vocational training, financial, family, and peer support will reduce the likelihood of experiencing stigma.
\end{abstract}

Keywords: Vietnam, Stigma, Discrimination, HIV/AIDS, Antiretroviral therapy

\section{Background}

The World Health Organization created 90-90-90 treatment goal as a global commitment: $90 \%$ of people living with HIV (PLWH) know their HIV status, 90\% of HIV-positive people receive antiretroviral treatment (ART), and $90 \%$ of PLWH on treatment have their viral loads suppressed [1]. Since then, ART has been an integral

\footnotetext{
* Correspondence: selena.ighi@gmail.com

${ }^{1}$ Institute for Global Health Innovations, Duy Tan University, Da Nang 550000, Vietnam

Full list of author information is available at the end of the article
}

part of HIV/AIDS control efforts to reduce disease burden and improve life expectancy of PLWH [2-4]. However, HIV-related stigma, which pertains to any discriminatory, prejudicial attitudes, and beliefs toward PLWH [4-7], remains the major challenge of the effectiveness of ART programs $[4,5,8]$. PLWH are subjected to stigma for its associated behaviors such as multiple sexual partners, injecting drugs, and having same-sex partners [9]. They are not only blamed for risky behaviors, but also are segregated for causing harm to society. Previous research among PLWH found that HIV disclosure was also 
associated with impaired psychological and emotional health conditions [9-12]. Fear of disclosure when accessing to HIV testing, care, treatment services, and associating peer support group may delay treatment initiation and hinder treatment adherence $[4,5,7,12]$.

Vietnam has made a significant progress in HIV/AIDS epidemic response for the last 25 years: preventing newly infected cases, reducing HIV/AIDS-related mortality and fatality, and expanding harm-reduction interventions and HIV services. According to UNAIDS, in 2017, Vietnam has approximately 250,000 PLWH, 50\% of those are receiving ART, and 43\% of PLWH are virally suppressed [13]. With these statistics, Vietnam is far from meeting its commitment which is to expand HIV treatment by 2020 , then become the first country in Asia to meet $90-90-90$ goal, and end the AIDS epidemic by 2030. As Vietnam becomes a middle-income country, many international donations are shrunk and slowly withdrawn from the country. Vietnam is trying to include HIV services in national health insurance with the hope of reducing stigma and discrimination of PLWH. However, the effectiveness of this strategy is still unknown because of the strong HIV stigma that remains in the community.

Vietnam has unique culture and social values that make HIV-related stigma toward PLWH more complex and dynamic. It is necessary to understand the phenomenon of bonding between individual and community in Vietnamese culture; socio-cultural values heavily affect HIV stigma. In literature, stigma toward PLWH in Vietnam has been fueled by the misconception about HIV, societal rejection, and judgment on HIV-related risky behaviors based on cultural and religious norms $[4-6,12,14-16]$. Since the very first attempt to raise awareness of and control HIV/AIDS, HIV/AIDS was portrayed as social evils to scare people away from risky behaviors [17]. With the given information on posters and banners, people believed HIV/AIDS was a death sentence. People became afraid of HIV infection and avoided any types of contacts with HIV-infected patients. Recently, even though the Government of Vietnam has shifted from a punitive to harm-reduction approach, the taboo regarding HIV/ AIDS remained. In addition, due to cultural and religious norms based on sexual orientation and sexual behaviors, the key HIV populations such as sex workers, drug user, and men who have sex with men are stigmatized even more because they are social evils, criminals, and immoral.

At the same time, despite many non-discrimination laws that have created to protect PLWH, these laws lack enforcement when incidents of violence [12], denial of care $[6,12,16]$, or hate crimes happen [5]. As the Government of Vietnam shifted from punitive to harm-reduction approach, sex worker and drug users are no longer sent to jail. Instead, they are sent to detention camps and rehabilitation centers where they are still within their communities and family members can visit them. Even though they are not considered as criminals, the fact that they are going to detention camps and rehabilitation centers indirectly disclose their behaviors and causes rumors that they have HIV/AIDS. Besides, in healthcare sector, HIV test results of patients were not always kept confidential, especially in lower health care administration [12]. Moreover, in a family-oriented culture like Vietnam, HIV/AIDS becomes a family disease which means not only the individuals but also their family and relatives are blamed, judged, and discriminated [12]. Previous research also found that PLWH isolated themselves to avoid stigma or discrimination, and perceived greater loneliness [9]. For a long time, it creates a chronic level of stress which causes psychological (e.g., anxiety, depression) and other health problems $[4,9,18]$. Because of all the following consequences and stigma, PLWH avoid disclosing their status with others.

HIV stigma deprives PLWH of the highest attainable health status in many ways, and it stands in the way of enhanced HIV services. In order to dispel stigma, we need to understand where it lies in the community. This study, therefore, aimed to explore current stigma in Vietnam experienced by ART patients regarding perception of being blamed or judged, feared of infection, ability to disclose HIV status, feeling shame, and discriminated. We also measured the degree of association between factors and perceived stigma. The findings may suggest directions to develop more effective policies and strengthen efforts to reduce stigma, improve treatment outcome and quality of life of ART patients, and to achieve 90-90-90 treatment goal.

\section{Methods \\ Study setting and subjects}

From January to August 2013, a cross-sectional study was conducted in Hanoi and Nam Dinh where two epicenters are providing HIV/AIDS control and treatment services in northern Vietnam. We selected eight outpatient clinics which met the following inclusion criteria: (1) the clinic belongs to the public health system in Vietnam (including central, provincial, and district levels), (2) the clinic provides ART service, and (3) the clinic implements their ART programs following the official guidelines from the Vietnamese Ministry of Health [19]. A total of eight outpatient clinics-five from Hanoi and three from Nam Dinh-were selected, including Bach Mai Hospital representing central administration level, Nam Dinh provincial hospital, and Nam Dinh provincial AIDS Control Centre representing provincial administration level, and five district health centers from 
Hoang Mai, Long Bien, Dong Anh, Ha Dong, Xuan, and Truong District.

Eligibility criteria for recruitment included (1) 18 years old and older, (2) having a confirmed HIV-positive test result, (3) enrolling or receiving ART at one of the selected clinics, (4) having no major cognitive impairment, and (5) agreeing to participate and providing written consent. The participants were excluded from the study if they had major cognitive impairment causing inability to answer the questionnaires. People who suffered from serious illness during the recruitment process were also excluded. The cognitive impairment and serious illness were determined by physician's diagnosis. A total of 1133 participants were recruited by convenience sampling method, and response rate was $80-90 \%$ across all sites. The participants decided not to participate in the study because of time conflict, discomfort, and poor physical health during the time of study.

Eligible patients were invited into a small counseling room for the interview. Using a structured questionnaire, the participants were interview via face-to-face for $20 \mathrm{~min}$. The interviewers were master students of public health at Hanoi Medical University. The students had experience working in HIV research study and were not affiliated with the participating clinics.

\section{Measures and instruments}

With the given context of HIV/AIDS in Vietnam, it is necessary to examine HIV-related stigma using a contextualized measure instrument. Therefore, we created a more contextualized questionnaire instead of using previous international stigma scale. The outcomes of this study were measured by five indicators of HIV/AIDS-related stigma according to USAID: (1) blame, judgment; (2) shame; (3) enacted stigma/discrimination; (4) disclosure; and (5) fear of casual transmission and refusal of contact [20]. Then we piloted the questionnaires among PLWH before interviewing participants.

During the interview, the participants were asked if they had experienced any of the above types of stigma within 30 days. The response options included (1) Yes, (2) No, and (3) No answer.

1. In general, have you recently been blamed or judged because of your health status?

2. Do you currently feel shame because of your health status?

3. Have you felt discriminated against or treated badly by others? In which circumstances (work place/all health facilities/family/community/others)?

4. Have you ever disclosed your health status with others? With whom did you share?

5. Has anyone expressed fear of contracting HIV from casual contacts with you?
We also collected participants' socioeconomic characteristics and ART treatment-related information. In addition, the participants were also asked whether they had peer support and attended peer-to-peer meeting.

\section{Socioeconomic characteristic}

The participants were asked to report age, gender, education level, marital status, religion, living place, and employment status.

\section{$A R T$ treatment-related information}

The participants were asked to report the latest CD4 cell count, HIV stage, ART duration, their needs of ART, whether they currently received treatment, and health-related quality of life (HRQOL). HRQOL was measured by using EuroQOL-5 dimensions-5 levels (EQ-5D-5 L) instrument in the Vietnamese version which was employed from a well-validated tool called EuroQol [21]. This tool assessed five domains including mobility, self-care, usual activities, pain/discomfort, and anxiety/depression. Each domain had five response levels: no problems, slight problems, moderate problems, severe problems, and extreme problems [22]. The combination of responses gives 3125 health index [21]. Furthermore, we employed 100-point visual analogue scale (EQ-VAS) to measure the self-reported HRQOL, ranging from 0 which was referred to "the worst health condition that you can imagine" to 100 which was referred to "the best health condition that you can imagine" [23].

\section{Statistical analysis}

STATA version 12 (Stata Corp. LP, College Station, United States of America) was employed to analyze data. Descriptive analysis such as $t$ test and chi-square were used to explore demographic characteristics of respondents as well as HRQOL, ART status, and stigmatization. A $p$ value $<0.05$ was used to determine statistical significance. Multivariate logistic regression was employed to identify factors associated with stigmatization. This strategy used threshold with the log-likelihood ratio test to have predictors with $p$ values of $<0.2$ included.

\section{Results}

Table 1 describes the socioeconomic characteristics of the respondents. Out of 1133 participants, more than half of participants were male $(58.7 \%)$, and the mean age was $35.3(\mathrm{SD}=6.9)$. The majority of the participants had secondary level education (36.9\%). Then, $20.4 \%$ of participants were currently unemployed; meanwhile, $41.1 \%$ of participants reported self-employed, $24.9 \%$ were workers or farmers, and $7.1 \%$ were white collars. More than three-quarters of participants lived in urban area (77.2\%), and practiced ancestral worship (88.4\%). 
Table 1 Socioeconomic characteristic of respondents

\begin{tabular}{|c|c|c|c|c|c|c|c|}
\hline & \multicolumn{2}{|l|}{ Single } & \multicolumn{2}{|c|}{$\begin{array}{l}\text { Live with } \\
\text { partner }\end{array}$} & \multicolumn{2}{|l|}{ Total } & \multirow[t]{2}{*}{$p$ value } \\
\hline & $n$ & $\%$ & $n$ & $\%$ & $n$ & $\%$ & \\
\hline \multicolumn{8}{|l|}{ Gender } \\
\hline Male & 205 & 46.6 & 460 & 66.4 & 665 & 58.7 & \multirow[t]{2}{*}{$<0.01$} \\
\hline Female & 235 & 53.4 & 233 & 33.6 & 468 & 41.3 & \\
\hline \multicolumn{8}{|l|}{ Education } \\
\hline Illiterate & 4 & 0.9 & 8 & 1.2 & 12 & 1.1 & \multirow[t]{6}{*}{0.48} \\
\hline Elementary & 90 & 20.5 & 130 & 18.8 & 220 & 19.4 & \\
\hline Secondary & 171 & 38.9 & 247 & 35.6 & 418 & 36.9 & \\
\hline High school & 135 & 30.7 & 227 & 32.8 & 362 & 32.0 & \\
\hline Vocational & 15 & 3.4 & 39 & 5.6 & 54 & 4.8 & \\
\hline University & 25 & 5.7 & 42 & 6.1 & 67 & 5.9 & \\
\hline \multicolumn{8}{|l|}{ Living place } \\
\hline Rural & 80 & 18.2 & 178 & 25.7 & 258 & 22.8 & \multirow[t]{2}{*}{$<0.01$} \\
\hline Urban & 360 & 81.8 & 515 & 74.3 & 875 & 77.2 & \\
\hline \multicolumn{8}{|l|}{ Religion } \\
\hline Cult of ancestors & 382 & 86.8 & 619 & 89.3 & 1001 & 88.4 & \multirow[t]{4}{*}{0.02} \\
\hline Buddhism & 23 & 5.2 & 32 & 4.6 & 55 & 4.9 & \\
\hline Catholic & 27 & 6.1 & 41 & 5.9 & 68 & 6.0 & \\
\hline Protestant & 8 & 1.8 & 1 & 0.1 & 9 & 0.8 & \\
\hline \multicolumn{8}{|l|}{ Employment } \\
\hline Unemployed & 110 & 25.0 & 121 & 17.5 & 231 & 20.4 & \multirow[t]{6}{*}{0.01} \\
\hline Self-employed & 165 & 37.5 & 304 & 43.9 & 469 & 41.4 & \\
\hline White collars & 23 & 5.2 & 57 & 8.2 & 80 & 7.1 & \\
\hline Workers, farmers & 110 & 25.0 & 172 & 24.8 & 282 & 24.9 & \\
\hline \multirow[t]{2}{*}{ Others } & 32 & 7.3 & 39 & 5.6 & 71 & 6.3 & \\
\hline & Mean & SD & Mean & SD & Mean & SD & \\
\hline Age & 34.7 & 0.3 & 36.0 & 0.3 & 35.5 & 6.9 & 0.50 \\
\hline
\end{tabular}

Regarding health-related quality of life, the most commonly reported problem was anxiety or depression (44.9\%), followed by pain or discomfort (37.7\%), and mobility (20.5\%). The average VAS score on quality of life was $68.8(\mathrm{SD}=17.3)$. These health problems were reported more among single HIV patients than those living with a partner (Table 2).

Table 3 illustrates that $42.1 \%$ of patients reported no HIV symptoms (42.1\%), and $96.0 \%$ patients currently using ART. The average CD4 cell count was 295 (SD = 215 ), and the average ART duration was 3.5 years (SD = 2.2). A half of respondents participated in peer-to-peer meeting (50.6\%); however, only $34.5 \%$ of participants perceived having support from their peers.

Table 4 shows different types of stigmatization experienced by participants. Further, $36.9 \%$ of participants reported experiencing shame, stigmatization blame/ judge (21.6\%), and discrimination (23.4\%).
Majority of participants were able to disclose their HIV status with others. There were more ART patients living with a partner reported disclosure than who were single. Single participants reported higher rate of stigma events than those who lived with partner.

Regression models in Table 5 indicate that having white collars jobs $(\mathrm{OR}=0.17, \mathrm{Cl}=0.005-0.58)$, not knowing $\mathrm{HIV}$ status ( $\mathrm{OR}=0.49, \mathrm{Cl}=0.33-0.74)$, quality of life were negatively associated with perceived discrimination. Meanwhile, suffering from pain or discomfort $(\mathrm{OR}=1.73, \mathrm{Cl}=1.17-2.56)$ was positively associated with perceived discrimination. Individuals with anxiety and depression were more likely to feel shame $(\mathrm{OR}=1.77, \mathrm{Cl}=1.29-2.41)$, discriminated (OR $=1.74, \mathrm{Cl}=1.18-2.58)$, and being mistreated due to the fear of $\mathrm{HIV}$ infection $(\mathrm{OR}=1.42, \mathrm{Cl}=1.03-1.97)$. Having unstable jobs $(\mathrm{OR}=2.33, \mathrm{Cl}=1.30-4.18)$ increased the likelihood of perceived shame, while being younger $(\mathrm{OR}=0.96, \mathrm{Cl}=0.94-0.99)$ increased the likelihood of perceived blame or judgment. Having mobility problems $(\mathrm{OR}=1.88, \mathrm{Cl}=1.20-2.93)$ did not only increase the likelihood of HIV patients being blamed or judged, but also decreased the likelihood of HIV status disclosure $(\mathrm{OR}=0.49, \mathrm{Cl}=0.27-0.91)$.

Regarding HIV status disclosure, HIV patients who had high school education level $(\mathrm{OR}=0.22, \mathrm{Cl}=0.07-$ $0.70)$ and reported having anxiety or depression $(\mathrm{OR}=$ $0.23, \mathrm{Cl}=0.11-0.48)$ were less likely to disclose their HIV status. In term of religion, PLWH who were Catholics would more likely to conceal their HIV status (OR = 0.35, $\mathrm{Cl}=0.15-0.80)$. At the same time, HIV patients those lived with a spouse or partner would more likely to disclose their HIV status $(\mathrm{OR}=1.91, \mathrm{Cl}=1.10-3.33$ ).

HIV patients who disclosed their HIV status were more likely to perceive discrimination $(\mathrm{OR}=3.82, \mathrm{Cl}=$ 1.84-7.95) and fear of HIV infection ( $\mathrm{OR}=3.21, \mathrm{Cl}=$ 1.59-6.50). Moreover, those practiced Buddhism (OR = $2.60, \mathrm{Cl}=1.32-5.12$ ) also reported higher odds of perceiving avoidance due to the fear of HIV infection. In contrast, those who did not know their HIV stage (OR = $0.54, \mathrm{Cl}=0.38-0.77$ ) and attended peer-to-peer meeting $(\mathrm{OR}=0.73, \mathrm{Cl}=0.54-0.98)$ were less likely to experience stigmatization related to the fear to HIV infection.

\section{Discussion}

Our study enriches the existing understanding of stigmatization experienced by ART patients in Vietnam. Considering it in a context of a family-oriented and closely bonded community, our study found that the likelihood of experiencing stigmatization was not only associated with the patients' socioeconomic and HIV status but also their health problems. Socioeconomic characteristics were associated with perceived shame, discrimination, ability to disclose HIV status, and fear of 
Table 2 Self-reported health-related quality of life

\begin{tabular}{|c|c|c|c|c|c|c|c|}
\hline & \multicolumn{2}{|l|}{ Single } & \multicolumn{2}{|c|}{ Live with partner } & \multirow{2}{*}{$\begin{array}{l}\text { Total } \\
n\end{array}$} & \multirow[b]{2}{*}{$\%$} & \multirow[t]{2}{*}{$p$ value } \\
\hline & $n$ & $\%$ & $n$ & $\%$ & & & \\
\hline \multicolumn{8}{|c|}{ Self-reported health problems } \\
\hline Mobility & 107 & 24.3 & 125 & 18.0 & 232 & 20.5 & 0.01 \\
\hline Self-care & 48 & 10.9 & 62 & 9.0 & 110 & 9.7 & 0.28 \\
\hline Usual activities & 85 & 19.3 & 103 & 14.9 & 188 & 16.6 & 0.05 \\
\hline Pain or discomfort & 194 & 44.1 & 233 & 33.6 & 427 & 37.7 & $<0.01$ \\
\hline \multirow[t]{2}{*}{ Anxiety or depression } & 237 & 53.9 & 272 & 39.3 & 509 & 44.9 & $<0.01$ \\
\hline & Mean & SD & Mean & SD & Mean & SD & \\
\hline VAS & 68.3 & 0.8 & 69.1 & 0.6 & 68.8 & 17.3 & 0.50 \\
\hline
\end{tabular}

HIV infection. The results also indicated that patients who disclosed HIV status were more likely to perceive discrimination and fear of HIV infection. Moreover, those with lower quality of life were at higher risk of perceived stigmatization across all five measured dimensions. Notably, our results could be used as effective approaches to dispel stigma barrier and improve quality of life of PLWH in Vietnam.

\section{Stigma}

Majority of participants reported perceived shame and fear of infection which is similar to what Gaudine et al.

Table 3 ART status

\begin{tabular}{|c|c|c|c|c|c|c|c|}
\hline & \multicolumn{2}{|l|}{ Single } & \multicolumn{2}{|c|}{ Live with partner } & \multirow{2}{*}{$\begin{array}{l}\text { Total } \\
n\end{array}$} & \multirow[b]{2}{*}{$\%$} & \multirow[t]{2}{*}{$p$ value } \\
\hline & $n$ & $\%$ & $n$ & $\%$ & & & \\
\hline \multicolumn{8}{|l|}{ HIV stage } \\
\hline No symptom & 185 & 43.4 & 271 & 41.3 & 456 & 42.1 & \multirow[t]{4}{*}{0.15} \\
\hline Have symptom & 86 & 20.2 & 107 & 16.3 & 193 & 17.8 & \\
\hline AIDS & 33 & 7.8 & 68 & 10.4 & 101 & 9.3 & \\
\hline Unknown & 122 & 28.6 & 210 & 32.0 & 332 & 30.7 & \\
\hline \multicolumn{8}{|l|}{ Need ART } \\
\hline Yes & 424 & 96.8 & 669 & 96.7 & 1093 & 96.7 & \multirow[t]{2}{*}{0.91} \\
\hline No & 14 & 3.2 & 23 & 3.3 & 37 & 3.3 & \\
\hline \multicolumn{8}{|l|}{ Using ART } \\
\hline Yes & 403 & 95.1 & 647 & 96.6 & 1050 & 96.0 & \multirow[t]{2}{*}{0.21} \\
\hline No & 21 & 5.0 & 23 & 3.4 & 44 & 4.0 & \\
\hline \multicolumn{8}{|l|}{ Peer-to-peer meeting } \\
\hline No & 198 & 46.9 & 346 & 51.0 & 544 & 49.5 & \multirow[t]{2}{*}{0.19} \\
\hline Yes & 224 & 53.1 & 332 & 49.0 & 556 & 50.6 & \\
\hline \multicolumn{8}{|l|}{ Have peer support } \\
\hline Yes & 166 & 37.7 & 225 & 32.5 & 391 & 34.5 & \multirow[t]{3}{*}{0.07} \\
\hline \multirow[t]{2}{*}{ No } & 274 & 62.3 & 468 & 67.5 & 742 & 65.5 & \\
\hline & Mean & SD & Mean & SD & Mean & SD & \\
\hline CD4 & 281 & 212 & 303 & 217 & 295 & 215 & \multirow[t]{2}{*}{0.49} \\
\hline ART duration (year) & 3.5 & 2.3 & 3.4 & 2.2 & 3.5 & 2.2 & \\
\hline
\end{tabular}

found in a study in 2010 [17]. In Vietnam, individuals with HIV were avoided, perceived anger and social rejection, and were viewed as a social ill. Their family members were shunned by neighbors, viewed as bad parents, experience financial hardship, and fear of HIV transmission. Community members and health professionals believed that HIV ruined family reputation, and they also avoid contact with HIV individuals [17]. HIV-related stigma causes PLWH faced problems of getting a job, receiving unfair treatment at work, and experiencing discrimination in healthcare setting [24]. After 8 years with extensive efforts, the experience associated with HIV-stigma remained till today.

\section{Associated factors Socioeconomic characteristics}

Our findings showed that patients who were younger were more likely to perceive blame or judge. Compared to older population, younger individuals work and involve in more social activities. Thus, they interact with others and are more prone to stigma. In Vietnamese culture, younger population, especially youth, is supposed to be pure. Because of HIV positive serostatus which could be due to mother-to-child transmission, the younger PLWH are often blamed or socially excluded [12, 25]. People believe that their family members or they commit a sin, so they are punished.

Similarly, having unstable jobs increased the likelihood of experiencing shame [26]. In Vietnamese culture, people often feel shame for not providing financial support to their family. Especially in the culture where everyone in the community connects, having unstable jobs also shames PLWH in the eyes of community [5] because the neighbors or others will questions why the individuals often quit their jobs. Unstable jobs also result from lower education level; PLWH suffer from stigma at school and quit early. Previous studies also found that PLWH have difficulty finding a job for long term partially due to HIV-related stigma at work from employers and co-workers [17]. It could be also caused by the time 
Table 4 Perceived stigmatization among ART patients

\begin{tabular}{|c|c|c|c|c|c|c|c|}
\hline & \multirow{2}{*}{$\begin{array}{l}\text { Single } \\
n\end{array}$} & \multirow[b]{2}{*}{$\%$} & \multicolumn{2}{|c|}{ Live with partner } & \multicolumn{2}{|l|}{ Total } & \multirow[t]{2}{*}{$p$ value } \\
\hline & & & $n$ & $\%$ & $n$ & $\%$ & \\
\hline \multicolumn{8}{|l|}{ Stigmatization } \\
\hline Blame/Judge & 94 & 22.9 & 138 & 20.9 & 232 & 21.6 & 0.43 \\
\hline Shame & 164 & 39.9 & 232 & 35.1 & 396 & 36.9 & 0.11 \\
\hline Discrimination & 123 & 28.0 & 142 & 20.5 & 265 & 23.4 & $<0.01$ \\
\hline Disclosure & 386 & 87.7 & 651 & 93.9 & 1037 & 91.5 & $<0.01$ \\
\hline Fear of HIV infection & 129 & 29.4 & 198 & 28.6 & 327 & 28.9 & 0.78 \\
\hline
\end{tabular}

Table 5 Associated factors

\begin{tabular}{|c|c|c|c|c|c|c|c|c|c|c|}
\hline & \multicolumn{2}{|c|}{ Blame/Judge } & \multicolumn{2}{|l|}{ Shame } & \multicolumn{2}{|c|}{ Discrimination } & \multicolumn{2}{|c|}{ Disclosure } & \multicolumn{2}{|c|}{ Fear of HIV infection } \\
\hline & $\mathrm{OR}$ & $95 \mathrm{Cl}$ & OR & $95 \mathrm{Cl}$ & $\mathrm{OR}$ & $95 \mathrm{Cl}$ & $\mathrm{OR}$ & $95 \mathrm{Cl}$ & $\mathrm{OR}$ & $95 \mathrm{Cl}$ \\
\hline \multicolumn{11}{|l|}{ Gender (Male-ref) } \\
\hline Female & & & & & $1.36^{*}$ & $(0.95-1.93)$ & & & & \\
\hline \multicolumn{11}{|l|}{ Education (Illiterate) } \\
\hline Secondary school & & & & & & & $0.37^{* * *}$ & $(0.21-0.68)$ & & \\
\hline High school & & & $0.35^{* *}$ & $(0.14-0.86)$ & & & $0.22^{* * *}$ & $(0.07-0.70)$ & & \\
\hline \multicolumn{11}{|l|}{ Marital status (Single-ref) } \\
\hline Live with spouse/partner & & & & & $0.72^{*}$ & $(0.51-1.01)$ & $1.91^{* *}$ & $(1.10-3.33)$ & & \\
\hline \multicolumn{11}{|l|}{ Religion (Cult of ancestors-ref) } \\
\hline Buddhism & & & & & & & & & $2.60^{* * *}$ & $(1.32-5.12)$ \\
\hline Catholic & & & $1.77^{*}$ & $(0.97-3.23)$ & & & $0.35^{* *}$ & $(0.15-0.80)$ & & \\
\hline \multicolumn{11}{|l|}{ Employment (Unemployed-ref) } \\
\hline White collars & & & & & $0.17^{* * *}$ & $(0.05-0.58)$ & & & & \\
\hline Workers, Farmers & & & $1.34^{*}$ & $(0.95-1.88)$ & $1.39^{*}$ & $(0.95-2.03)$ & & & & \\
\hline Other & & & $2.33^{* * *}$ & $(1.30-4.18)$ & & & & & $0.51^{*}$ & $(0.24-1.06)$ \\
\hline \multicolumn{11}{|l|}{ Self-reported health problems } \\
\hline $\begin{array}{l}\text { Having problem with mobility } \\
\text { (Yes vs No) }\end{array}$ & $1.88^{* * *}$ & $(1.20-2.93)$ & & & & & $0.49^{* *}$ & $(0.27-0.91)$ & & \\
\hline Pain or discomfort (Yes vs No) & & & & & $1.73^{* * *}$ & $(1.17-2.56)$ & & & & \\
\hline $\begin{array}{l}\text { Anxiety or depression (Yes vs } \\
\text { No) }\end{array}$ & & & $1.77^{* * *}$ & $(1.29-2.41)$ & $1.74^{* * *}$ & $(1.18-2.58)$ & $0.23^{* * *}$ & $(0.11-0.48)$ & $1.42^{* *}$ & $(1.03-1.97)$ \\
\hline \multicolumn{11}{|l|}{ HIV period (No symptom-ref) } \\
\hline Have symptom & & & $1.47^{*}$ & $(0.99-2.18)$ & & & & & & \\
\hline AIDS & & & & & $1.70^{* *}$ & $(1.02-2.85)$ & & & & \\
\hline Unknown & & & $0.72^{*}$ & $(0.51-1.00)$ & $0.49^{* * *}$ & $(0.33-0.74)$ & $2.21^{* *}$ & $(1.06-4.58)$ & $0.54^{* * *}$ & $(0.38-0.77)$ \\
\hline \multicolumn{11}{|l|}{ Peer-to-peer meeting (No-ref) } \\
\hline Yes & & & & & & & & & $0.73^{* *}$ & $(0.54-0.98)$ \\
\hline \multicolumn{11}{|l|}{ Disclosure (No-ref) } \\
\hline Yes & & & & & $3.82^{* * *}$ & $(1.84-7.95)$ & & & $3.21^{* * *}$ & $(1.59-6.50)$ \\
\hline Age & $0.96^{* * *}$ & $(0.94-0.99)$ & $0.98^{*}$ & $(0.96-1.00)$ & & & & & & \\
\hline VAS & $0.97^{* * *}$ & $(0.96-0.98)$ & $0.99^{* * *}$ & $(0.98-0.99)$ & $0.98^{* * *}$ & $(0.97-0.99)$ & & & $0.98^{* * *}$ & $(0.97-0.99)$ \\
\hline
\end{tabular}


conflict between ART clinic and their work hours. On the same side, we found that white collars were less likely to perceive discrimination, which is consistent with previous study [4]. This could be explained by the fact that white collars usually work with highly educated co-workers and their workplace complies with HIV-privacy laws.

In the present study, the likelihood of HIV status disclosure was negatively correlated with education level. Unlikely, the previous research found those who were educated more would be more likely to reveal HIV status [27]. This could be explained by the fact that those with higher education are well educated about HIV, control their conditions, and cope with HIV better [28]. Therefore, they may not feel necessary to disclose their HIV status to others.

\section{Health problems}

Our study found that quality of life was negatively associated with stigma. Quality of life does not only pertain to living or health conditions but also perception. In previous studies, quality of life of PLWH was extensively examined and found to be a risk factor of perceived and enacted stigma, physical and mental health problems $[8$, $9,12,29]$. Numerous studies have found the bidirectional relationship between anxiety or depression and HIV-related stigma $[9,18]$. In our study, having anxiety and depression decreased the likelihood of disclosing HIV status and increased the likelihood of perceiving shame, discrimination, and fear of HIV infection. Previous research found that the risk of depression was four times higher among those who did not disclose their HIV status than their counterpart [18]. In a culture like Vietnam where people live closely in a community, HIV-related stigma makes PLWH constantly worried and anxious because they do not know how they will be treated and what people think about them. Especially after seeing how other HIV-infected individuals are treated, those have yet disclosed would kept confidential to avoid stigma. At the same time, PLWH are often isolated by community, or PLWH isolate themselves to avoid being stigmatized and discriminated [9]. Thus, the individuals develop negative feelings or emotions [18] and avoid anything associated with HIV/AIDS such as accessing to testing and HIV treatments [7]. Notably, this particular population deserves more attentions from community and clinicians.

In addition, our findings also showed that patients who had mobility problems would experience more blame or judgment. Meanwhile, perceived discrimination was reported more among those with pain or discomfort and AIDS [29]. Moreover, Vietnamese people believe in "You reap what you sow." People believe that having physical problems, pains, or disgusting AIDS symptoms are consequences of PLWH's immoral behaviors. Also, either mobility problems, pain and discomfort, or AIDS symptoms exhibit outside; thus, others could easily see, and then judge or discriminate the individuals.

\section{HIV status disclosure}

Disclosing HIV status potentially helps to control HIV/ AIDS epidemics by preventing HIV infection, increasing access to HIV-related services, and ensuring treatment adherence [30]. However, the decision to disclose HIV status is challenging to PLWH due to stigma and the fear of HIV infection [31, 32]. In this study, those did not know their HIV status and live with spouse or partners were more likely to disclose their HIV status. This could be explained by the fact that PLWH choose to disclose their HIV status to receive testing, treatments, and prevent HIV infection [3, 29, 30]. Previous study found that disclosure increases the likelihood of safe sex to keep the partner from infection [33, 34]. However, some people choose to disclose their HIV status to engage in unprotected sex with other HIV-positive partners [35].

Our results also indicated that those who disclosed HIV status had almost four times more likely to report perceive discrimination and fear of infection than those did not disclose, which is consistent with previous research $[5,31$, 35, 36]. Discrimination might be the rejection from sexual partner, family, friends, and community because they are afraid of infection [35]. Eventually, it will affect treatment adherence and health outcomes $[6,12,32,37]$.

\section{Peer support}

In this study, peer-to-peer meeting had no association with either perceived blame/judge, shame, discrimination, or HIV disclosure. However, peer-to-peer meeting decreased the odds of experiencing fear of infection from others. Being in a group of people who share a common experience or diagnosis provides HIV-positive individuals sense of social acceptance, reciprocal support, and empowerment [38]. As their self-esteem and self-confidence arise, they perceive less fears, uncertainties, and stigma [39].

\section{Implications}

We found that individuals with unstable jobs were three times more likely to perceive shame. Providing convocational training and appropriate jobs to stabilize income of PLWH will benefit them and their family. Instead of perceiving shame when they are financial burden of family, having a job gives individuals a sense of pride and success. Being employed and having a secured job significantly improved physical and mental health-related quality of life among adults living with HIV [40]. In addition, anti-HIV-related discrimination regulations should be enforced at workplaces. Posters and formal announcements should be made to employer and employees. This 
will allow PLWH to reintegrate into community as they work, and encourages them to access HIV-related care services when they less worry about what to do for living.

Providing peer support reduces the stigma associated with HIV and empower HIV-positive individuals [38, 39]. However, our findings indicated that our current peer support program was not effective enough to reduce HIV-related stigmatization in Vietnam. We might need a more holistic approach to create a social support system within community and society: increase knowledge and awareness, create positive attitudes, and implement social support. Mass media campaigns sustainably increase health-related knowledge and produce positive changes across large populations [41]. Previous studies demonstrated the positive correlation between mass media campaigns and condom use, HIV transmission, and prevention knowledge [42, 43]. In Vietnam, HIV-related stigma is largely due to the misconception about HIV. Thus, the information campaigns will help to correct the wrong information and promote positive attitudes toward HIV/AIDS and PLWHA. However, mass campaigns can only have an effect on certain segments of population due to knowledge gap between those with high and low education level [44]. Therefore, it is important to ensure the mass media campaign is available and accessible, and the presenting information is tailored to different segment of population. Also, in illiterate or low health literacy community, community-based participatory programs and interpersonal community activities using social and religious networks can be useful [45]. This comes from the compassion and sympathy of society, family, and beloved ones toward ART patients.

An ultimate goal of reducing stigma among PLWHA is to improve their health. However, more efforts are required to improve health status of individuals with chronic illness, especially with stigmatized illness and depressive symptoms. First, physicians should screen for depressive symptoms among PLHWA, and provide counseling. Second, we should develop community-based interventions to promote psychosocial well-being among PLWHA. Wu and Li found that support group which provides emotion and information support, mentoring, and community involvement increased positive social interaction, and reduced HIV/ AIDS-related stigma, distress, depression, anger, and anxiety $[46,47]$. These community-based interventions should consider contextual factors, have high frequency of follow ups, and last for a long period of time [48]. As individuals improve their mental health and perceive social acceptance, they will be in charge of their health, stay adhered to their treatment, and improve health outcomes.

\section{Strengths and limitations}

The study recruited large amount of participants from Hanoi and Nam Dinh which are epicenters of HIV epidemics in Vietnam. However, there are several limitations that need to be considered when interpreting the results. First, health problems and stigmatization were self-reported. The information could have been underor over-reported due to recall and social desirability response bias. Second, due to the nature of cross-sectional study, the study could not establish the causal relationship between stigmatization and its associated factors. This problem could be eliminated if researcher could perform longitudinal study. Third, the participants were recruited by convenience sampling method which may reduce the generalizability of the study.

\section{Conclusion}

In conclusion, our findings illustrated that stigma was not only associated with socioeconomic characteristics but also other health problems. HIV status disclosure also increased the likelihood of discrimination and stigmatization related to fear of HIV infection. There is a need of interventions targeting PLWH with anxiety and depression. Increasing quality of life of PLWH by providing vocational training, financial, and family and peer support will decrease the likelihood of experiencing stigmatization.

\section{Abbreviations \\ AIDS: Acquired immune deficiency syndrome; ART: Antiretroviral treatment; EQ-5D-5 L: EuroQOL-5 dimensions-5 levels; EQ-VAS: Visual analogue scale; HIV: Human immunodeficiency virus; HRQOL: Health-related quality of life; PLWH: People living with HIV}

\section{Acknowledgements}

The authors would like to acknowledge supports by the Vietnam Authority of HIV/AIDS Control for the implementation of the study.

Funding

There was no funding for this analysis.

Availability of data and materials

The data that support the findings of this study are available from the Vietnam Authority of HIV/AIDS Control but restrictions apply to the availability of these data, which were used under license for the current study, and so are not publicly available. Data are however available from the authors upon reasonable request and with permission of Vietnam Authority of HIV/ AIDS Control.

\section{Authors' contributions}

PQTT, BXT, CTN, NTT, TPTT, CAL, CSHH, and RCMH conceived of the study, and participated in its design and implementation and wrote the manuscript. $\mathrm{PQTT}, \mathrm{BXT}$, and CTN analyzed the data. All authors read and approved the final manuscript.

\section{Ethics approval and consent to participate}

The protocol of this study was reviewed and approved by the Vietnam Authority of HIV/AIDS Control's Scientific Research Committee. The purpose of study, the benefits, and drawbacks of participation were introduced to the participants. The participants were also informed that they could withdraw from the study at any time and withdrawing from the study would not affect their service at the clinics. If they agreed to participate, they would sign a written consent form. We ensured confidentiality of participants at all time of the study.

Consent for publication

Not applicable. 


\section{Competing interests}

The authors declare that they have no competing interests.

\section{Publisher's Note}

Springer Nature remains neutral with regard to jurisdictional claims in published maps and institutional affiliations.

\section{Author details}

Institute for Global Health Innovations, Duy Tan University, Da Nang 550000 Vietnam. ${ }^{2}$ Institute for Preventive Medicine and Public Health, Hanoi Medical University, Hanoi, Vietnam. ${ }^{3}$ Bloomberg School of Public Health, Johns Hopkins University, Baltimore, MD, USA. ${ }^{4}$ Center of Excellence in Behavioral Medicine, Nguyen Tat Thanh University, Ho Chi Minh City, Vietnam. ${ }^{5}$ Department of General Planning and Department of Cardiology, Friendship Hospital, Hanoi, Vietnam. ${ }^{6}$ Department of Psychological Medicine, National University Hospital, Singapore, Singapore. ${ }^{7}$ Department of Psychological Medicine, Yong Loo Lin School of Medicine, National University of Singapore, Singapore, Singapore.

\section{Received: 9 June 2018 Accepted: 4 January 2019}

\section{Published online: 17 January 2019}

\section{References}

1. Organization WH. Treatment 2.0: catalyzing next phase of scale-up, decentralized. Geneva: Integrated and Community-Centered Service Delivery; 2011

2. Mbonye M, Nakamanya S, Birungi J, King R, Seeley J, Jaffar S. Stigma trajectories among people living with HIV (PLHIV) embarking on a life time journey with antiretroviral drugs in Jinja, Uganda. BMC Public Health. 2013; 13:804.

3. Tran BX, Nguyen LT, Nguyen NH, Hoang QV, Hwang J. Determinants of antiretroviral treatment adherence among HIV/AIDS patients: a multisite study. Glob Health Action. 2013;6:19570

4. UNAIDS:: On the fast-track to end AIDS by 2030: focus on location and population. 2015.

5. Thanh DC, Moland KM, Fylkesnes K. Persisting stigma reduces the utilisation of HIV-related care and support services in Viet Nam. BMC Health Serv Res. 2012;12:428.

6. Pharris A, Hoa NP, Tishelman C, Marrone G, Kim Chuc NT, Brugha R, Thorson A. Community patterns of stigma towards persons living with HIV: a population-based latent class analysis from rural Vietnam. BMC Public Health. 2011;11:705.

7. Tran DA, Shakeshaft A, Ngo AD, Rule J, Wilson DP, Zhang L, Doran C. Structural barriers to timely initiation of antiretroviral treatment in Vietnam: findings from six outpatient clinics. PLoS One. 2012;7:e51289.

8. Rangarajan S, Tram HNB, Todd CS, Thinh T, Hung V, Hieu PT, Hanh TM, Chau KM, Lam ND, Hung PT. Risk factors for delayed entrance into care after diagnosis among patients with late-stage HIV disease in southern Vietnam. PLoS One. 2014:9:e108939.

9. Nachega JB, Morroni C, Zuniga JM, Sherer R, Beyrer C, Solomon S, Schechter $\mathrm{M}$, Rockstroh J. HIV-related stigma, isolation, discrimination, and serostatus disclosure: a global survey of 2035 HIV-infected adults. J Int Assoc Physicians AIDS Care (Chic). 2012;11:172-8.

10. Chan B, Tsai A, Siedner M: Has anti-retroviral treatment scale-up in subSaharan Africa reduced HIV-related stigma in the general population. In A cross-country analysis Seattle: Conference on Retroviruses and Opportunistic Infections 2015.

11. Treves-Kagan S, Steward WT, Ntswane L, Haller R, Gilvydis JM, Gulati H, Barnhart S, Lippman SA. Why increasing availability of ART is not enough: a rapid, community-based study on how HIV-related stigma impacts engagement to care in rural South Africa. BMC Public Health. 2015;16:87.

12. Van Tam V, Pharris A, Thorson A, Alfven T, Larsson M. "It is not that I forget, it's just that I don't want other people to know": barriers to and strategies for adherence to antiretroviral therapy among HIV patients in northern Vietnam. AIDS Care. 2011;23:139-45.

13. Country factsheets: Vietnam 2017 HIV and AIDS estimates [http://www. unaids.org/en/regionscountries/countries/vietnam]

14. Koo FK, Chow EPF, Gao L, Fu X, Jing J, Chen L, Zhang L. Socio-cultural influences on the transmission of HIV among gay men in rural China. Cult Health Sex. 2014;16(3):302-15.
15. Zang C, Guida J, Sun Y, Liu H. Collectivism culture, HIV stigma and social network support in Anhui, China: a path analytic model. AIDS Patient Care STDs. 2014;28:452-8.

16. Hatzenbuehler ML, Phelan JC, Link BG. Stigma as a fundamental cause of population health inequalities. Am J Public Health. 2013;103:813-21.

17. Gaudine A, Gien L, Thuan TT, Dungdo V. Perspectives of HIV-related stigma in a community in Vietnam: a qualitative study. Int J Nurs Stud. 2010;47:38-48.

18. Rodkjaer L, Chesney MA, Lomborg K, Ostergaard L, Laursen T, Sodemann M. HIV-infected individuals with high coping self-efficacy are less likely to report depressive symptoms: a cross-sectional study from Denmark. Int J Infect Dis. 2014;22:67-72.

19. Health VMo: Decision No 3003/QD-BYT on issuing "Guideline for HIV diagnosis and treatment". 2009.

20. USAID. Can we measure HIV/AIDS-related stigma and discrimination? Current knowledge about quantifying stigma in developing countries, vol. 28; 2006. p. 28

21. Tran BX, Ohinmaa A, Nguyen LT. Quality of life profile and psychometric properties of the EQ-5D-5L in HIV/AIDS patients. Health Qual Life Outcomes. 2012;10:132.

22. GLOBOCAN 2012: Cervical cancer estimated cancer incidence, mortality and prevalence worldwide in 2012 [http://globocan.+iarc.fr/Pages/fact_sheets_ cancer.aspx?cancer=cervix\#]

23. Ternent LMP, Newlands D. Exploring biases in the double bounded dichotomous choice (DBDC) and DBDC with open ended follow-up methods; 2010.

24. Thi MD, Brickley DB, Vinh DT, Colby DJ, Sohn AH, Trung NQ, Giangle T, Mandel JS. A qualitative study of stigma and discrimination against people living with HIV in Ho Chi Minh City, Vietnam. AIDS Behav. 2008;12:S63-70.

25. Hong KT, Van Anh NT, Ogden J. "Because this is the disease of the century": understanding HIV and AIDS-related stigma and discrimination in Vietnam. International center for research on women (ICRW); 2004

26. Tsai AC, Bangsberg DR, Weiser SD. Harnessing poverty alleviation to reduce the stigma of HIV in sub-Saharan Africa. PLoS Med. 2013;10:e1001557.

27. Akani $\mathrm{Cl}$, Erhabor O. Rate, pattern and barriers of HIV serostatus disclosure in a resource-limited setting in the Niger delta of Nigeria. Trop Dr. 2006:36:87-9.

28. Liping M, Peng X, Haijiang L, Lahong J, Fan L. Quality of life of people living with HIV/AIDS: a cross-sectional study in Zhejiang Province, China. PLoS One. 2015;10:e0135705.

29. Tran BX. Quality of life outcomes of antiretroviral treatment for HIV/AIDS patients in Vietnam. PLoS One. 2012;7:e41062.

30. Mall S, Middelkoop K, Mark D, Wood R, Bekker LG. Changing patterns in HIV/AIDS stigma and uptake of voluntary counselling and testing services: the results of two consecutive community surveys conducted in the Western cape, South Africa. AIDS Care. 2013:25:194-201.

31. Przybyla SM, Golin CE, Widman L, Grodensky CA, Earp JA, Suchindran C. Serostatus disclosure to sexual partners among people living with HIV: examining the roles of partner characteristics and stigma. AIDS Care. 2013; 25:566-72.

32. French $H$, Greeff M, Watson MJ, Doak CM. HIV stigma and disclosure experiences of people living with HIV in an urban and a rural setting. AIDS Care. 2015;27:1042-6.

33. Holt R, Court P, Vedhara K, Nott KH, Holmes J, Snow MH. The role of disclosure in coping with HIV infection. AIDS Care. 1998;10:49-60.

34. Simoni JM, Pantalone DW. Secrets and safety in the age of AIDS: does HIV disclosure lead to safer sex? Top HIV Med. 2004;12:109-18.

35. Parsons JT, VanOra J, Missildine W, Purcell DW, Gomez CA. Positive and negative consequences of HIV disclosure among seropositive injection drug users. AIDS Educ Prev. 2004;16:459-75.

36. Smith R, Rossetto K, Peterson BL. A meta-analysis of disclosure of one's HIVpositive status, stigma and social support. AIDS Care. 2008;20:1266-75.

37. Qiao S, Li X, Zhou Y, Shen Z, Tang Z, Stanton B. Factors influencing the decision-making of parental HIV disclosure: a socio-ecological approach. AIDS. 2015;29(Suppl 1):S25-34.

38. Marino P, Simoni JM, Silverstein LB. Peer support to promote medication adherence among people living with HIV/AIDS: the benefits to peers. Soc Work Health Care. 2007:45:67-80.

39. Michielsen K, Beauclair R, Delva W, Roelens K, Van Rossem R, Temmerman $M$. Effectiveness of a peer-led HIV prevention intervention in secondary schools in Rwanda: results from a non-randomized controlled trial. BMC Public Health. 2012;12 
40. Rueda S, Raboud J, Rourke SB, Bekele T, Bayoumi A, Lavis J, Cairney J, Mustard C. Influence of employment and job security on physical and mental health in adults living with HIV: cross-sectional analysis. Open Med. 2012;6:e118-26.

41. Wakefield MA, Loken B, Hornik RC. Use of mass media campaigns to change health behaviour. Lancet. 2010;376:1261-71.

42. LaCroix J, Snyder LB, Huedo-Medina T, Johnson BT. Effectiveness of mass medica interventions for HIV prevention, 1986-2013: a meta-analysis. JAIDS Journal of Acquired Immune Deficiency Syndromes. 2014;66:S329-40.

43. Bertrand JT, O'Reily K, Denison J, Anhand R, Sweat M. Systematic review of the effectiveness of mass communication programs to change HIV/AIDSrelated behaviors in developing countries. Health Educ Res. 2006;21:567-97.

44. Bekalu MA, Eggermont S. Media use and HIV/AIDS knowledge: a knowledge gap perspective. Health Promot Int. 2014;29:739-50.

45. Hendriksen ES, Hlubinka D, Chariyalertsak S, Chingono A, Gray G, Mbwambo J, Richter L, Kulich M, Coates TJ. Keep talking about it: HIV/AIDS-related communication and prior HIV testing in Tanzania, Zimbabwe, South Africa, and Thailand. AIDS Behav. 2009;13:1213-21.

46. Wu L, Li X. Community-based HIV/AIDS interventions to promote psychosocial well-being among people living with HIV/AIDS: a literature review. Health Psychol Behav Med. 2013;1:31-46.

47. Matsumoto S, Yamaoka K, Takahashi K, Tanima J, Mizushima D, Do CD, Nguyen TD, et al. Social support as a key protective factor against depression in HIV-infected patients: report from large HIV clinics in Hanoi, Vietnam. Sci Rep. 2017;7(1):15489.

48. Sikkema KJ, Dennis AC, Watt MH, Choi KW, Yemeke TT, Joska JA. Improving mental health among people living with HIV: a review of intervention trials in low- and middle-income countries. Glob Ment Health (Camb). 2015;2:e19.

Ready to submit your research? Choose BMC and benefit from:

- fast, convenient online submission

- thorough peer review by experienced researchers in your field

- rapid publication on acceptance

- support for research data, including large and complex data types

- gold Open Access which fosters wider collaboration and increased citations

- maximum visibility for your research: over $100 \mathrm{M}$ website views per year

At $\mathrm{BMC}$, research is always in progress.

Learn more biomedcentral.com/submissions 